\title{
Chlorogenic acid in the oxidative stress injury triggered by Shuang-Huang-Lian injection
}

\author{
WEN-YUAN DU ${ }^{1 *}$, YING XIAO $^{2 *}$, JIAN-JING YAO $^{1}$, ZHE HAO $^{3}$ and YU-BIN ZHAO ${ }^{1}$ \\ ${ }^{1}$ Medical and Electronic Experimental Center, The TCM Hospital of Shijiazhuang \\ Affiliated to Hebei University of Chinese Medicine, Shijiazhuang, Hebei 050051; \\ ${ }^{2}$ Institute of Chemical Engineering, Shijiazhuang University, Shijiazhuang, Hebei 050035; \\ ${ }^{3}$ The Third Hospital of Shijiazhuang, Shijiazhuang, Hebei 050011, P.R. China
}

Received January 1, 2018; Accepted July 26, 2018

DOI: $10.3892 /$ etm.2018.6567

\begin{abstract}
Injections of Chinese herbs are a novel approach to prepare traditional Chinese medicines. However, as injections of Chinese herbs have been extensively used, adverse drug reactions (ADRs) have been on the increase. Additionally, the mechanism for injections of Chinese herbs remains unclear. This study explored the potential role played by chlorogenic acid (CGA) in initiating oxidative stress injury triggered by the utilization of injections of Chinese herbs and the underlying mechanism. A total of 90 male Wistar rats were raised for varying periods by using Shuang-Huang-Lian (SHL) injection or CGA in diverse dosages. Western blot analysis examined the expression of nicotinamide adenine dinucleotide phosphate oxidase subunits, spectrophotometry was used to examine the activity taken by catalase, ELISA was used to examine the concentrations of inflammatory factors in serum, and intravital microscopy was employed to examine the microcirculation. The results showed that the excessive peroxide production induced by CGA in high-dose or SHL in the venule walls may well be through nicotinamide adenine dinucleotide phosphate oxidase along with a decline in the activity of catalase, and led to imbalance of basal levels of pro-(TNF- $\alpha$ ) and anti-(IL-10) inflammatory cytokines. On the basis of the aforementioned results, the mechanism hidden behind the adverse effects of CGA induced by irrational use of Chinese herbal injection can be identified from a deeper perspective.
\end{abstract}

Correspondence to: Dr Yu-Bin Zhao, Medical and Electronic Experimental Center, The TCM Hospital of Shijiazhuang Affiliated to Hebei University of Chinese Medicine, 233 Zhongshan West Road, Shijiazhuang, Hebei 050051, P.R. China

E-mail: zhaoyubin12@163.com

*Contributed equally

Key words: reactive oxygen species, Chinese herbal injection, chlorogenic acid, NADPH oxidase, drug safety

\section{Introduction}

The Chinese herbal injections are new preparations of novel approaches to prepare traditional Chinese herbal medicines designed within the past decade for convenience in practice in terms of practitioners and patients. However, as injections of Chinese herbs have been extensively used, there has been an increase un adverse drug reactions (ADRs), including drug-induced death, liver and kidney injury, shock, diarrhea, vomiting, asthma, erythra, and itchy skin (1-5). Such preparations, guided by a qualified practitioner of TCM, should have mild and low adverse effects, as previously documented (2). The majority of these ADRs however, correlate with irrational use especially overdose $(2,6,7)$. In recent years, increasing attention has been paid to the mechanisms for ADRs. Nevertheless, little information is available on the constituent complexity of these injections.

Chlorogenic acid (CGA) is a ubiquitous component in most Chinese herbal injections, also usually employed as a typical marker to control the quality of TCM (8), such as Shuang-Huang-Lian (SHL) injection (according to the Pharmacopeia of China, 2005). This field remains problematic $(9,10)$ though the allergenicity has constantly counted as the primary factor leading to adverse effects of CGA $(11,12)$. On the other hand, CGA in lower concentrations eliminated hydroxyl radical and superoxide in vitro although CGA at higher concentrations produced radicals and served as a pro-oxidant, as previously reported (13). Oxidative damage to normal cells is likely to be one of the mechanisms of such drug-induced adverse reaction, which may be a good interpretation for why herbal injection-induced ADRs occur in the case of overdose more often than not (6). Nevertheless, which insults are bound by the adverse effects triggered by CGA remain unclear.

The present study determined the functions taken on by CGA in the oxidative stress injury triggered by injections of Chinese herbs by controlling SHL injection in different doses, i.e., the most frequently used and ADRs reported on Chinese herbal injections (14), and equivalent dose of CGA, respectively. The experimental flow diagram is shown in Fig. 1. 


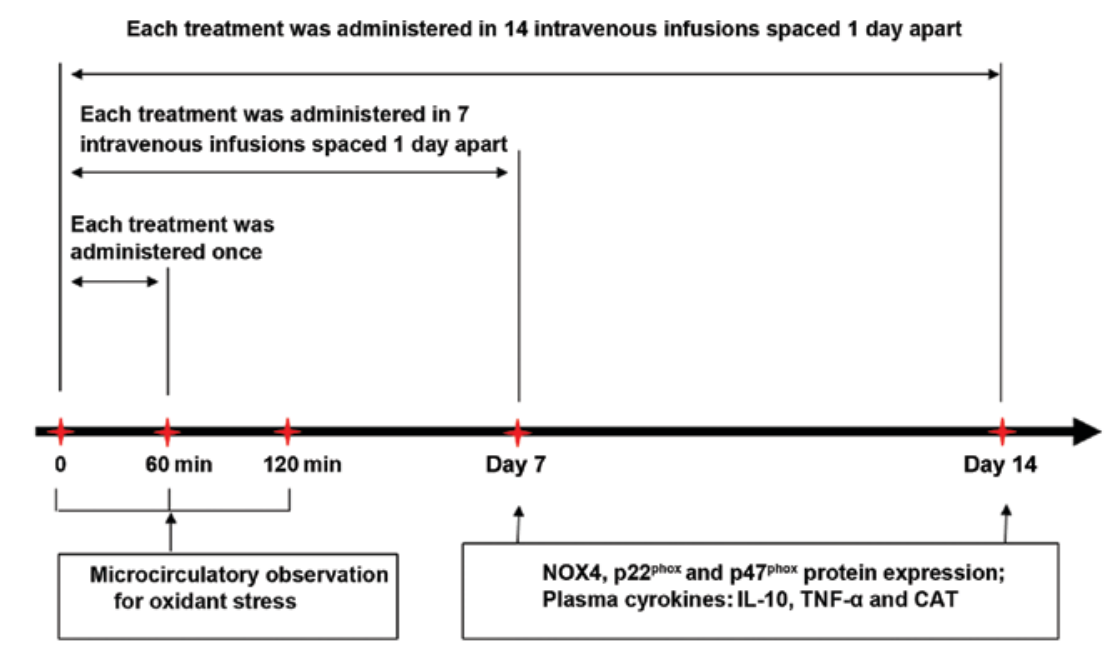

Figure 1. The experimental flow diagram. IL-10, interleukin-10; TNF- $\alpha$, tumor necrosis factor- $\alpha$.

\section{Materials and methods}

Animals and reagents. A total of 90 male Wistar rats with a weight ranging 200-220 g were obtained from the Animal Center, Health Science Center, Peking University (Beijing, certificate no. SCXK 2006-0008). The rats were caged as per a 12-h light/dark circulation $40 \pm 5 \%$ of humidity and at $22 \pm 2^{\circ} \mathrm{C}$, and given standard water and diet without advance preparation. Prior to the experiment, the rats were fasted for $12 \mathrm{~h}$. The animal model preparation, under the guidance of Animal Research Committee of Peking University, complied with the EU adopted Directive 2010/63/EU. Experimental Animal Ethics Branch subordinated by Biomedical Ethics Committee governed by Peking University approved the experiment protocols (LA2011-38). The study was also approved by the Ethics Committee of the TCM Hospital of Shijiazhuang Affiliated to Hebei University of Chinese Medicine (Shijiazhuang, China).

CGA was dissolved in sterile $0.9 \%$ normal saline, which was obtained from Sigma-Aldrich: Merck KGaA (St. Louis, MO, USA) with a purity $>98 \%$. SHL lyophilized powder injection (24 ampoules, $1.2 \mathrm{~g}$ /ampoule) was obtained from Heilongjiang Songhuajiang Pharmaceuticals Co., Ltd. (Harbin, China) also dissolved in $0.9 \%$ normal saline.

Drug administration and experimental groups. This study randomly split the rats into five groups according to weight. Additionally, the high-dose SHL injection [H-SHL; $420 \mathrm{mg} / \mathrm{kg}, 8 \mathrm{ml} / \mathrm{kg} / \mathrm{h}$, intravenous (i.v.) drip injection], high-dose CGA (H-CGA; $7 \mathrm{mg} / \mathrm{kg}, 8 \mathrm{ml} / \mathrm{kg} / \mathrm{h}$, i.v. drip injection), low-dose SHL injection (L-SHL; $20 \mathrm{mg} / \mathrm{kg}, 8 \mathrm{ml} / \mathrm{kg} / \mathrm{h}$, i.v. drip injection), low-dose CGA (L-CGA; $0.336 \mathrm{mg} / \mathrm{kg}, 8 \mathrm{ml} / \mathrm{kg} / \mathrm{h}$, i.v. drip injection) and normal saline (control, $8 \mathrm{ml} / \mathrm{kg} / \mathrm{h}$, i.v. drip injection) were given within $1 \mathrm{~h}$ via the left catheter of jugular vein, respectively. The body weight CGA with the concentration of $0.336 \mathrm{mg} / \mathrm{kg}$ was selected as a low dose as being a mean dosage of CGA in injection of Chinese herb being most frequently adopted. In addition, the adverse effect relative to this dose has been rarely reported. The dose recommended in the instructions of Qingkaling injection, an injection of traditional Chinese medicine, takes up merely $1 / 6$ of the dose $7 \mathrm{mg} / \mathrm{kg}$ body weight. Additionally, the majority of the found adverse effects occur close to this dose (15). The L-SHL and the H-SHL group contained the same amount of CGA $(0.336$ and $7 \mathrm{mg} / \mathrm{kg}$, according to the Pharmacopeia of China, 2005) as L-CGA or H-CGA group, respectively. This study administered animals in another isolated experiment series by adopting saline or the drug whereby intraperitoneal bolus injection QD was for 7 or 14 days. Furthermore, the relevant examinations on the animals were carried out. Table I lists the animal number in line with the groups for the experiment.

Microcirculatory observation. Surgery was performed, complying with the previous descriptions (16). This study used intramuscular injection of $20 \%$ urethane $(1 \mathrm{ml} / 100 \mathrm{~g} \mathrm{BW})$, anesthetizing the rats. The abdomen of rats was opened via a 25 to $30 \mathrm{~mm}$ cut. The ileocecal junction of the mesentery was gently exposed (10-15 cm caudal) outside. On that basis, the exposed junction was mounted on a plastic transparent stage for rats. Through continuous superfusion, the mesentery was preserved moist and warm at $37^{\circ} \mathrm{C}$ with saline solution. An inverted microscope (DM IRB; Leica Microsystems GmbH, Cologne, Germany) was used to observe the microcirculation of mesentery via the objective lens (x20), and a $12 \mathrm{~V}$, $100 \mathrm{~W}$, direct current-stabilized light source was used to transilluminate the mesentery. A video camera with vibrant color (JK-TU53H; Toshiba, Tokyo, Japan) was installed on the microscope to capture the images from the microscopic angle. Subsequently, the image was transmitted onto a monitor (J2118A; TCL, Huizhou, China). A digital video disk video cassette recorder (DVR-R25; Malata, Xiamen, China) recorded the images. Single and unbranched venules (30-50 $\mu \mathrm{m}$ in diameter; $200 \mu \mathrm{m}$ in length) were selected for the study (16).

After the observation of baseline (10 min), microcirculation was examined. For monitoring oxidant stress in the venule walls, $5 \mathrm{~min}$ before observation, topical dihydrorhodamine oxidant-sensitive, 123 fluorescent probe was applied to the surface of mesentery $(10 \mu \mathrm{mol} / \mathrm{l})$ (DHR; Molecular Probes: Thermo Fisher Scientific, Inc., Eugene, OR, USA). A fluorescence microscope inverted for $455 \mathrm{~nm}$ excitation light (DM IRB; Leica Microsystems $\mathrm{GmbH}$ ), to record the fluorescence image 60 and $120 \mathrm{~min}$ after infusion at baseline. 
Table I. No. of animals for different experimental groups and various parameters.

\begin{tabular}{|c|c|c|c|}
\hline Groups & $\begin{array}{c}\text { Oxidant } \\
\text { stress }\end{array}$ & $\begin{array}{c}\text { Western blotting, } \\
\text { ELISA and } \\
\text { biochemical examination }\end{array}$ & Total \\
\hline \multicolumn{4}{|l|}{$2 \mathrm{~h}$} \\
\hline Control & 6 & - & 6 \\
\hline L-CGA & 6 & - & 6 \\
\hline L-SHL & 6 & - & 6 \\
\hline H-CGA & 6 & - & 6 \\
\hline H-SHL & 6 & - & 6 \\
\hline \multicolumn{4}{|l|}{ Day 7} \\
\hline Control & - & 6 & 6 \\
\hline L-CGA & - & 6 & 6 \\
\hline L-SHL & - & 6 & 6 \\
\hline H-CGA & - & 6 & 6 \\
\hline H-SHL & - & 6 & 6 \\
\hline \multicolumn{4}{|l|}{ Day 14} \\
\hline Control & - & 6 & 6 \\
\hline L-CGA & - & 6 & 6 \\
\hline L-SHL & - & 6 & 6 \\
\hline H-CGA & - & 6 & 6 \\
\hline H-SHL & - & 6 & 6 \\
\hline Total & 30 & 60 & 90 \\
\hline
\end{tabular}

The same animals from each group were used for the determination of oxidant stress. For western blotting, ELISA and biochemical examination, tissues were collected from the same animals in each group. $2 \mathrm{~h}$, one injection; day 7, 7 injections; day 14, 14 injections; L-CGA, lowdose CGA; L-SHL, low-dose SHL; H-CGA, high-dose CGA; H-SHL, high-dose SHL.

Additionally, this study employed Image-Pro Plus 5.0 software to, respectively, measure the extravenular interstices (Ie) and fluorescence intensity of walls venule (Iv). How Ie and Iv were different from each other was ascertained for each point of time. Besides, the ratio of each value calculated to the baseline (16).

ELISA analysis. After injections for 7 or 14 days, the blood was extracted from a branch of the descending aorta of the rats. For measuring the concentrations of tumor necrosis factor- $\alpha$ (TNF- $\alpha$ ) and interleukin-10 (IL-10), $1 \mathrm{ml}$ arterial systemic serum was collected. Using ELISA kits from RapidBio Systems, Inc. (Carlsbad, CA, USA), the concentrations of TNF- $\alpha(\mathrm{pg} / \mathrm{ml})$ and IL-10 $(\mathrm{pg} / \mathrm{ml}$ serum) were ascertained. The assays were conducted as instructed by the manufacturer (17).

Determination of activity of catalase. After 7 or 14 days of injection, the serum was collected and the blood extracted from a branch of the descending aorta of rats. The activity by catalase (CGAT) was evaluated by exposing samples to excessive hydrogen peroxide with the purpose of decomposition Additionally, to produce a comoles compound, was reacted with the ammonium molybdate with the residual hydrogen peroxide, which was absorbed at $405 \mathrm{~nm}$ to the greatest extent (18). The the antioxidase activities as $\mathrm{U} / \mathrm{ml}$ serum were noted. Through commercial kits, the assessments of CGAT activity was performed (Nanjing Jiancheng Bioengineering Institute, Nanjing, China). A bicinchoninic acid (BCA) protein assay kit was used to analyze the overall content of protein in samples (Sun Biomedical Technology Co., Ltd, Beijing, China) (18).

Western blotting of Nox4, $p 22^{\text {phox }}, p 47^{\text {phox }}$ protein expression. The lung tissues, brain tissues and tissues of terminal ileum of rats were removed 7 or 14 days after injection. Tissues were homogenized and minced in lysis buffer on ice [pH 7.4, $0.1 \%$ sodium dodecyl sulfate (SDS), $1 \%$ Nonidet p40 (NP40) solution, $50 \mathrm{mM}$ Tris/ $\mathrm{HCl}$, and $150 \mathrm{mM} \mathrm{NaCl}$ ], and centrifuged for $10 \mathrm{~min}$ at $12,000 \mathrm{x} \mathrm{g}$. The supernatant was isolated with cytosol proteins. BCA protein assay kit was used to study and quantified the overall protein in the homogenates (Sun Biomedical Technology Co., Ltd.). The prepared samples were boiled for $5 \mathrm{~min}$ in gel loading buffer [pH 6.8, $1 \%$ bromophenol blue, $1.56 \%$ dithiothreitol (DTT), $10 \%$ glycerol, $2 \%$ SDS, and $12.5 \mathrm{mM}$ Tris/HCl]. The proteins $(50 \mu \mathrm{g})$ were separated in equal amounts for each sample on a mini-gel of 10\% SDS-polyacrylamide for $2 \mathrm{~h}$ at a constant voltage of $100 \mathrm{~V}$. The proteins were transferred to membranes of polyvinylidene difluoride (PVDF) through electrophoresis for $16 \mathrm{~h}$ at $30 \mathrm{~V}$. The membranes were blocked at room temperature in TBS-T in 5\% (w/v) non-fat dry milk for $1 \mathrm{~h}(\mathrm{pH}$ 7.4, $0.1 \mathrm{mM}$ Tween-20, $100 \mathrm{mM} \mathrm{NaCl}$, and $10 \mathrm{mM}$ Tris/HCl). The membranes were cultured through using rabbit polyclonal IgG against $\beta$-actin (1:500), p47 $7^{\text {phox }}(1: 200)$, p22 $2^{\text {phox }}(1: 200)$ (all from Santa Cruz Biotechnology, Inc., Santa Cruz, CA, USA), Nox4 [2 $\mu \mathrm{g} / \mathrm{ml}$; Abcam (Hong-Kong), Ltd., Hong-Kong, China] overnight. The samples were washed, and the membranes cultures for $2 \mathrm{~h}$ through the secondary antibodies conjugated by enzyme used in immunohistochemistry to label antigens and their antibodies (1:3,000; Santa Cruz Biotechnology, Inc.). Radiographic film was subsequent exposured and a chemiluminescence system was enhanced, and detected the antibody labeling. The optical density was visualized for the bands. Besides, the density was normalized to the density taken by $\beta$-actin (19).

Statistical analysis. Data were presented as the mean \pm standard error (SEM). Additionally, SPSS 17.0 software for statistics was employed for analysis (SPSS, Inc., Chicago, IL, USA). Multiple comparisons were made using ANOVA followed by Tamhane's T2 and LSD tests. This study accepted statistical significance at $\mathrm{p}<0.05$.

\section{Results}

Determination of intensity of fluorescence by DHR in the walls of venules. The intensity of fluorescence by DHR in the walls of venules at diverse times in the five groups were determined. In rat mesenteric walls of venule, we failed to detect DHR fluorescence prior to infusing the five groups. Additionally, the low fluorescence intensity remained in the L-SHL, L-CGA and control group. Conversely, a marked DHR fluorescence was triggered by H-CGA in walls of the venules for $60-120 \mathrm{~min}$ as the groups were infused taking on evident 

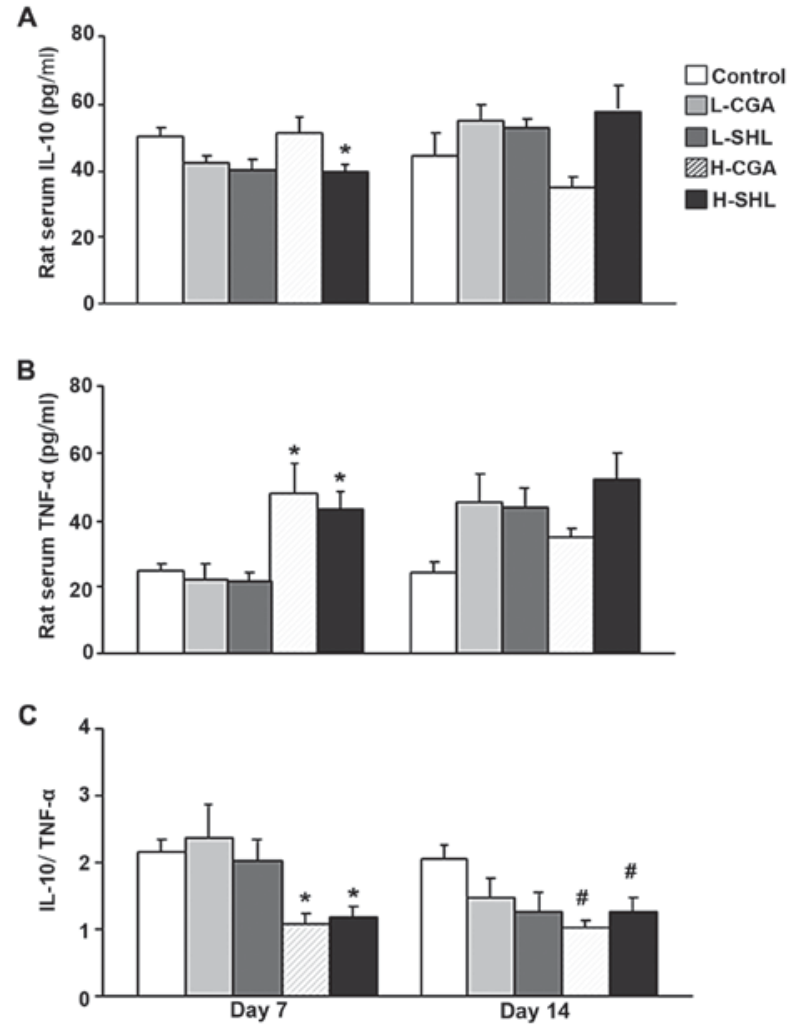

Figure 2. Concentrations of IL-10 and TNF- $\alpha$ in rat serum. (A) IL-10 content (pg/ml); (B) TNF- $\alpha$ content (pg/ml); (C) the ratio of IL-10 to TNF- $\alpha$. Data are expressed as mean \pm SEM of six animals. "P<0.05 vs. control group (day 7), ${ }^{\#} \mathrm{p}<0.05$ vs. control group (day 14). IL-10, interleukin-10; TNF- $\alpha$, tumor necrosis factor- $\alpha$; L-CGA, low-dose CGA; L-SHL, low-dose SHL; H-CGA, high-dose CGA; H-SHL, high-dose SHL.

difference in contrast with control group. Likewise, H-SHL induced an obvious DHR fluorescence at $120 \mathrm{~min}$ in contrast with control group and a little under the H-CGA group level, which indicated the inherent capacity by CGA and SHL to trigger reactive oxygen species (ROS) production at high dose from venules.

Analysis of IL-10, TNF- $\alpha$ and CGAT in rat serum. Inflammatory factor parameters in rat serum were recorded according to the experimental protocol. The changes of IL-10, TNF- $\alpha$, IL-10/TNF- $\alpha$ and CGAT in rat serum at day 7 and 14 are shown in Figs. 2 and 3. H-SHL suppressed the concentration of IL-10 after seven injections compared with control. Furthermore, the expression of TNF- $\alpha$ was significantly higher in H-CGA and $\mathrm{H}$-SHL group than that in control group at day 7 , and no significant change was found in proinflammatory cytokines at day 14 point. Moreover, the ratio of IL-10 and TNF- $\alpha$ decreased in H-CGA group at day 7 and 14 as compared to control group, and, the ratio decreased in response to injection with $\mathrm{H}-\mathrm{SHL}$, which was similar to the change in H-CGA group at the two time points (Fig. 2).

The CGAT in the antioxidant principle pertaining to the organism was contained. As shown in Fig. 3, the activity of CGAT decreased in H-CGA and H-SHL group after seven injections. At day 14 time point, the activity of CGAT similarly decreased in the two groups. Other groups did not affect the activity of the enzyme during the observation.

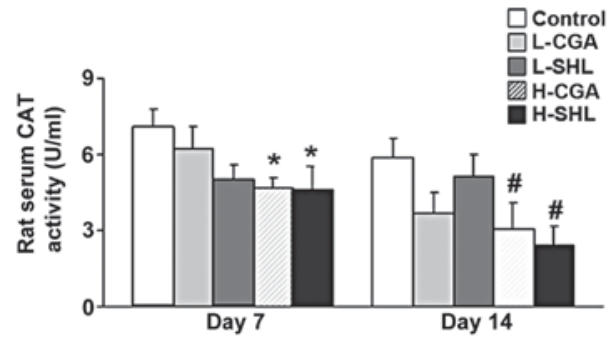

Figure 3. The concentrations of CAT in rat serum. CAT activity analysis $(\mathrm{U} / \mathrm{ml})$. Data are expressed as mean $\pm \mathrm{SEM}$ of six animals. ${ }^{*} \mathrm{P}<0.05$ vs. control group (day 7), ${ }^{\#} \mathrm{p}<0.05$ vs. control group (day 14). L-CGA, low-dose CGA; L-SHL, low-dose SHL; H-CGA, high-dose CGA; H-SHL, high-dose SHL.

Determination of Nox $4, p 22^{\text {phox }}$, and $p 47^{\text {phox }}$ protein expression in the tissues. To consider the function endowed with nicotinamide adenine dinucleotide phosphate oxidase in CGA taking on high dose and SHL-triggered production of ROS from circulatory system, the expression of the three subunits of nicotinamide adenine dinucleotide phosphate oxidase at protein level in the terminal ileum, $\mathrm{p} 47^{\text {phox }} \mathrm{p} 22^{\text {phox }}$ and Nox4, lung and brain tissues, and the results are shown in Figs. 4-6. At the two time points examined, no diversification was indicated as the foregoing proteins were expressed between L-SHL, L-CGA and control group. Comparatively, CGA in high dose facilitated the expression at day 7 and 14 studied for the protein Nox4 in the terminal ileum tissues, and similarly H-SHL increased the expression of Nox4 at day 7 in the same tissue. H-CGA also enhanced protein $\mathrm{p} 22^{\text {phox }}$ and p4 $7^{\text {phox }}$ expression at day 7 time point (Fig. 4). In the brain tissues, injection with H-CGA or H-SHL has the same effect increasing $\mathrm{p} 47^{\text {phox }}$ protein expression at day 7. Furthermore, H-SHL also enhanced protein Nox4 expression at the same time point (Fig. 6).

\section{Discussion}

Injecting SHL or CGA in high dose probably result in an inbalance between mechanism in antioxidant and oxidant, which was proven in this study in rats. Such injection triggers oxidant stress, inclusive of gained ROS production in wall of venules, and decreased activity of CGAT. Promoted expression of $\mathrm{p} 47^{\text {phox }}, \mathrm{p} 22^{\mathrm{phox}}$ and Nox4 was observed in response to the injection of SHL or CGA in high dose, indicating the containment of nicotinamide adenine dinucleotide phosphate oxidase in the CGA-triggered oxidant stress. Moreover, exposure to H-CGA or SHL undermined the balance of basal levels of pro-(TNF- $\alpha$ ) and anti-(IL-10) inflammatory cytokines, manifested as decreased IL-10 to TNF- $\alpha$ ratio. As overdose drugs were added, adverse effects observed overall showed up.

For monitoring the oxidative stress, the probe DHR was employed on the basis of fluoresce and sensitive to $\mathrm{H}_{2} \mathrm{O}_{2}$ to ascertain extent of ROS in other types and intracellular $\mathrm{H}_{2} \mathrm{O}_{2}$ levels in other cell types and in incubated endothelial cells (20-22). As outcomes acquired in this report indicate, imbalance between the systemic manifestation of ROS in microcirculatory system was promoted in both groups of SHL and CGA taking on high dose starting from 60 and $120 \mathrm{~min}$ administration, respectively. However, injection with CGA 
A

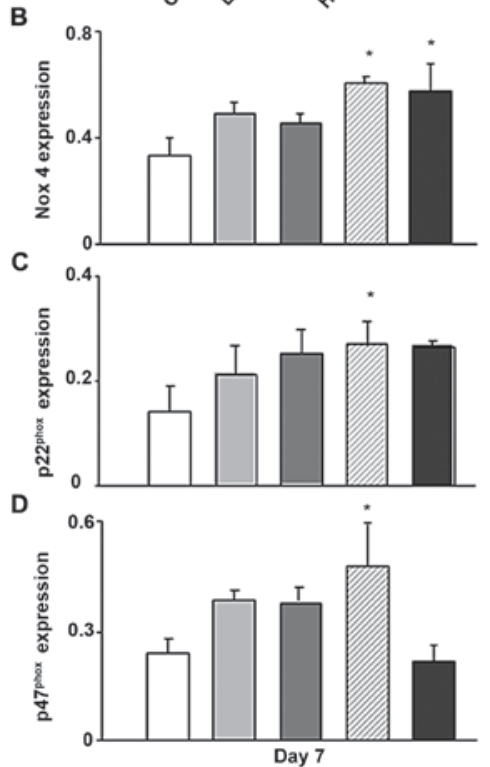

$\mathrm{E}$
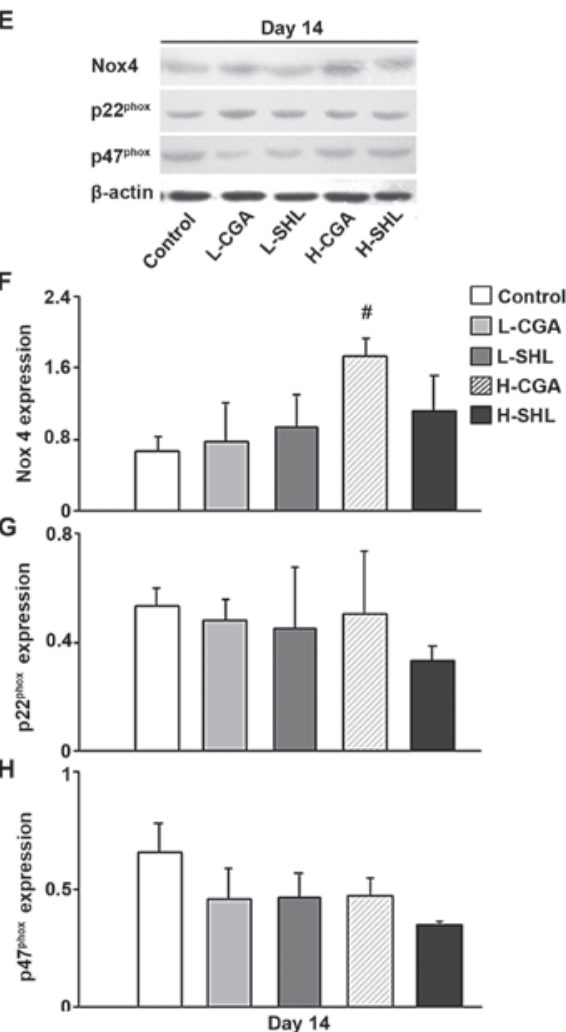

Figure 4. The protein expression of Nox4, p22 $2^{\text {phox }}$ and p47 phox in the ileum tissues of rats. (A and E) Representative western blots of Nox4, p22 $2^{\text {phox }}$ and p47 $7^{\text {phox }}$ at day 7 and 14. The protein expression of (B and F) Nox4, $(\mathrm{C}$ and $\mathrm{G}) \mathrm{p} 22^{\text {phox }}$, and $(\mathrm{D}$ and $\mathrm{H}) \mathrm{p} 47^{\text {phox }}$ at day 7 and 14. Lower columns: quantification of the western blotting results shown in (A and E). Data are expressed as means \pm SEM of three animals. ${ }^{*} \mathrm{P}<0.05$ vs. control group (day 7 ), ${ }^{\# p}<0.05$ vs. control group (day 14$)$. L-CGA, low-dose CGA; L-SHL, low-dose SHL; H-CGA, high-dose CGA; H-SHL, high-dose SHL.

A

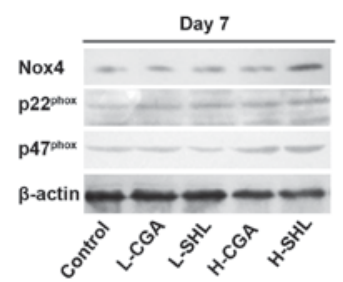

B

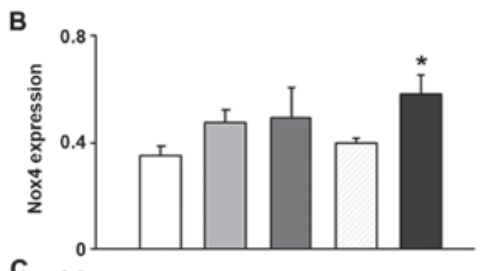

C$$
\text { 政 }
$$
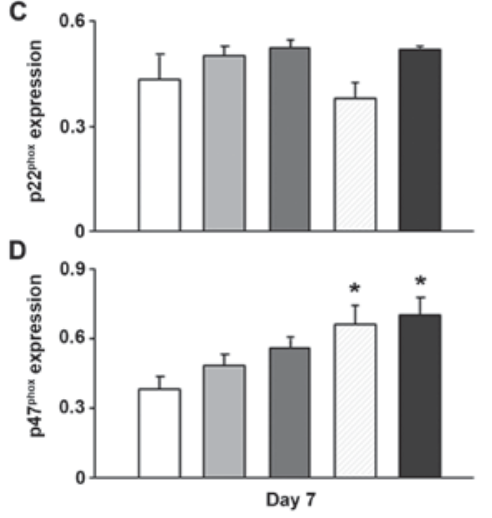

E
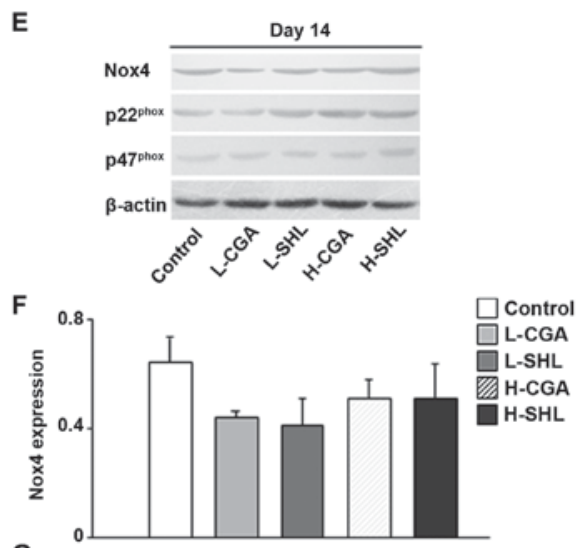

G

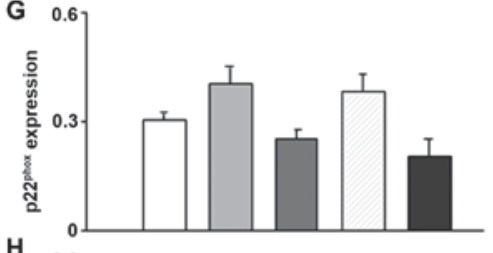

$\mathbf{H}$

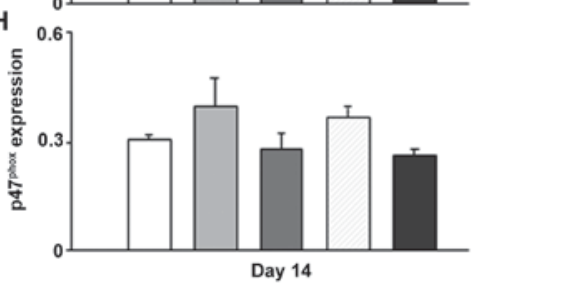

Figure 5. The protein expression of Nox4, p22 phox and p47 phox in the lung tissues of rats. (A and E) Representative western blots of Nox4, p22 phox and p47 phox at day 7 and 14. The protein expression of (B and F) Nox4, (C and G) p22 phox , and (D and H) p47 $7^{\text {phox }}$ at day 7 and 14. Lower columns: quantification of the western blotting results shown in (A and E). Data are expressed as means \pm SEM of three animals. "P<0.05 vs. control group (day 7). L-CGA, low-dose CGA; L-SHL, low-dose SHL; H-CGA, high-dose CGA; H-SHL, high-dose SHL. 
A

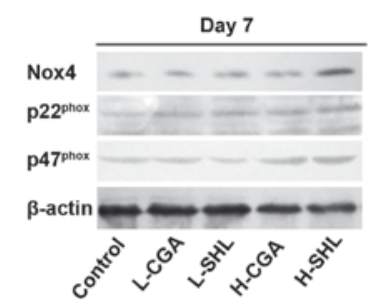

B

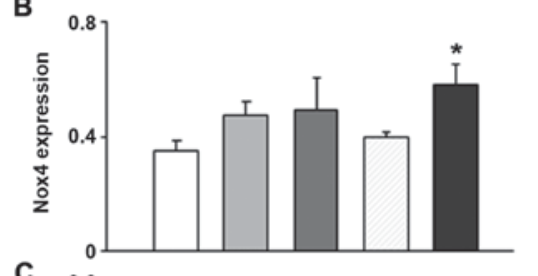

E
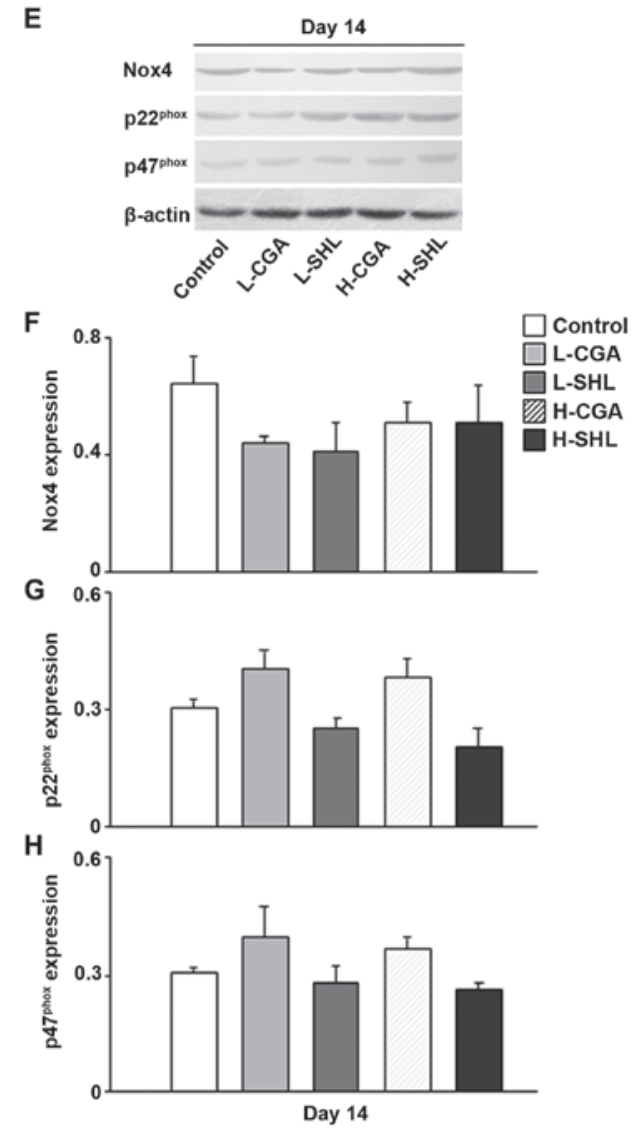

Figure 6. The protein expression of Nox4, p22 $2^{\text {phox }}$ and p47phox in the brain tissues of rats. (A and E) Representative western blots of Nox4, p22 $2^{\text {phox }}$ and $\mathrm{p} 47^{\text {phox }}$ at day 7 and 14. The protein expression of (B and F) Nox4, (C and G) p22 phox and (D and H) p47phox at day 7 and 14 . Lower columns: quantification of the western blotting results shown in (A and E). Data are expressed as means \pm SEM of three animals. ${ }^{*} \mathrm{P}<0.05$ vs. control group (day 7). L-CGA, low-dose CGA; L-SHL, low-dose SHL; H-CGA, high-dose CGA; H-SHL, high-dose SHL.

or SHL in low dose did not enhance the generation of ROS. This finding was consistent with previous research (23). CGA-triggered oxidative stress depends on the dose.

As the presented, CGA or SHL in high dose evidently declined the activity of antioxidase CGAT in rat serum after 7 and 14 day injections. An equilibrium between clearance and ROS production is of necessity for the standard cellular roles. As the antioxidant capacity of ROS is overcome by its cellular production, the equilibrium is broken, and an imbalance between the systemic manifestation of ROS shows up. CGAT counts as the primary antioxidant in cells produced by an enzyme and is of critical significance for offering protection against stress generated in oxidation (24). This antioxidase can be evidently depleted, and its activity is remarkably reduced as ROS is excessively accumulated. This finding conformed to the outcomes detected in terms of intensity of fluorescence relative to DHR (over ROS production). Accordingly, the injury by oxidant stress exerted by high-dose drug is probably triggered by dissipation of the antioxidant enzymes and ROS over production.

Scholars have always considered ROS over production as a pathological process charged with organ dysfunction and cellular damage (19). Given the necessity to take by nicotinamide adenine dinucleotide phosphate oxidase in producing stress related to oxidation of dysregulated vascular oxidation-reduction circumstance (25), we investigated nicotinamide adenine dinucleotide phosphate oxidase family members and explored the potential of the enzyme as the source of high dose CGA or SHL-induced ROS. It was found that H-CGA and SHL significantly increased Nox4, p22 ${ }^{\text {phox }}$ or $\mathrm{p} 47^{\text {phox }}$ protein expression in the terminal ileum, lung and brain tissues after 7 or 14 day injections. It was reported that Nox4 is present in all vascular walls and is significantly more abundant than any other Nox enzyme (26). The high expression of Nox $4, \mathrm{p} 22^{\text {phox }}$ and $\mathrm{p} 47^{\text {phox }}$ suggests that nicotinamide adenine dinucleotide phosphate oxidase plays a role in high dose CGA and SHL-induced ROS production especially derived from vascular walls. Even so, the possibility remains for the involvement of other peroxidases present and other mechanisms in vascular cells induced by CGA or SHL overdose.

This study observed a decrease of IL-10/TNF- $\alpha$ ratio in the high dose CGA and SHL group after 7 and 14 day injections, which suggested that the balance between IL-10 and TNF- $\alpha$ tipped towards inflammation. The ratio between IL-10 and TNF- $\alpha$ has been used as an accurate estimate of the inflammatory activity in the systemic circulation (27). IL-10 demonstrates potent anti-inflammatory properties through inhibiting the production of TNF- $\alpha$ and other pro-inflammatory cytokines (28). It has revealed to possess antioxidant-like properties in situations where oxidative stress is increased (29). On the other hand, TNF- $\alpha$ enhances oxidative stress both by increasing ROS generation as well as 
by decreasing antioxidants. Moreover, it has been postulated that the balance between pro- and anti-inflammatory cytokines would be related with $\mathrm{NF}-\kappa \mathrm{B}$ mediation (30). In this experiment, we also measured the protein expression of this factor and found that NF- $\mathrm{NB}$ p 65 protein expression was increased in the lung and brain tissues when exposed to high-dose CGA or SHL injection (further study is in progress). $\mathrm{NF}-\kappa \mathrm{B}$ is one of the most important regulators of pro-inflammatory cytokines inclusive of TNF- $\alpha$, IL-1 $\beta$, IL-6, IL-8, and platelet activation factor gene transcription $(31,32)$. IL-10 acts as a natural antagonist to TNF- $\alpha$, by inhibiting $\mathrm{NF}-\kappa \mathrm{B}$ signaling through the preservation of inhibitory factor $\kappa \mathrm{B}(\mathrm{I} \kappa \mathrm{B})(30)$. Additionally, IL-10 alleviated inflammatory stimulus mediated increase in ROS (33) and ROS mediated $\mathrm{I} \kappa \mathrm{B}$ degradation and thus activation of NF- $\kappa \mathrm{B}(29)$. In general, cytokines are interwoven and regulated through a feedback mechanism (34), which suggests that other inflammatory cytokines or mediators may be present in high-dose CGA and SHL induced oxidant stress or inflammatory injury.

In summary, the present study documented the potential role of CGA in SHL injection overdose induced generating excessive peroxide in vascular endothelial cells may well be through nicotinamide adenine dinucleotide phosphate oxidase and imbalance of basal levels of pro-(TNF- $\alpha$ ) and anti-(IL-10) inflammatory cytokines. These results illuminate mechanisms underlying the unfavorable effects of CGA induced by irrational use of Chinese herbal injection, and carefully reckon with the clinician particularly as an injection of TCM involving high level of CGA is adopted. We concluded that SHL injection induced excessive generation of peroxides and imbalance between TNF- $\alpha$ and IL-10 at high dose, which can be partly attributed to CGA.

\section{Acknowledgements}

We gratefully acknowledge the excellent technical assistance of Professor Jing-yan Han of Peking University.

\section{Funding}

This study was supported by grant no. 90709052 from the National Natural Science Foundation of China and the Production of New Medicine Program of Ministry of Science and Technology of the People's Republic of China (2008ZX09101-027) for Professor Peng-Tao Li based on the Ministry of Education and Key laboratory of Chinese Internal Medicine and Scientific and Technological Innovation Team of Beijing University of Chinese Medicine.

\section{Availability of data and materials}

The datasets used and/or analyzed during the current study are available from the corresponding author on reasonable request.

\section{Authors' contributions}

WYD was responsible for the production of animal models, revising and writing of the manuscript. YX contributed in the calculation of the indexes. JJY, ZH and YBZ were responsible for the collection of the data, the modification of the pictures and a part of the statistical analysis. YZ was responsible for revising and finalizing this report. All the authors read and approved the final manuscript.

\section{Ethics approval and consent to participate}

This study was approved by the Ethics Committee of the TCM Hospital of Shijiazhuang Affiliated to Hebei University of Chinese Medicine (Shijiazhuang, China).

\section{Patient consent for publication}

Not applicable.

\section{Competing interests}

The authors declare that they have no competing interests.

\section{References}

1. Ai CL, Xie YM, Li MQ, Wang LX and Liao X: Incidence rate of adverse reaction/event by Qingkailing injection: A Meta-analysis of single rate. Zhongguo Zhong Yao Za Zhi 40: 4770-4778, 2015 (In Chinese).

2. Wang WP, Yu M, Wang L, Jiang XR, Li XB, Wang HW, Cao Y, Liu K and Huang LQ: Academic discussion of adverse reaction of clinical trials of new traditional Chinese medicines and relevant influencing factors. Zhongguo Zhong Yao Za Zhi 40: 346-350, 2015 (In Chinese).

3. Tan LJ, Wang M and Zhu Y: Research progress of adverse reactions of traditional Chinese medicine injections. Zhongguo Zhong Yao Za Zhi 39: 3889-3898, 2014 (In Chinese).

4. Li BQ, Dong X, Yang GQ, Fang SH, Gao JY, Zhang JX, Gu FM, Miao XM and Zhao H: Role of chlorogenic acid in the toxicity induced by Chinese herbal injections. Drug Chem Toxicol 33: 415-420, 2010.

5. Wang ZF, Zhao W, Zhang Y and Xie YM: Analysis of influencing factors on adverse reaction of Shengfu injection based on prospective active safety monitoring. Zhongguo Zhong Yao Za Zhi 40: 4746-4751, 2015 (In Chinese).

6. Chang YP, Huo J, Xie YM, Zhang H and Zhuang Y: Real world study of affect on liver function of overdose of salvianolate extract injection. Zhongguo Zhong Yao Za Zhi 38: 3092-3098, 2013 (In Chinese).

7. Wang ZF, Ai QH, Li YY, Jiang JJ, Wang LX, Yang W and Xie YM: Analysis of the allergic reaction types of Chinese medicine injection based on immunotoxicty. Zhongguo Zhong Yao Za Zhi 40: 4762-4765, 2015 (In Chinese).

8. Huang FH, Zhang XY, Zhang LY, Li Q, Ni B, Zheng XL and Chen AJ: Mast cell degranulation induced by chlorogenic acid. Acta Pharmacol Sin 31: 849-854, 2010.

9. Layton LL, Panzani R and Cortese TA: Coffee-reaginic human sera tested in human volunteers and macaque monkeys. Absence of reactions to chlorogenic acid. Int Arch Allergy Appl Immunol 33: 417-427, 1968.

10. Layton LL, Panzani R, Greene FC, Green TW and Smith JD: Castor bean allergy as cross-reactive hypersensitivity to the spurges (euphorbiaceae): Absence of reaction to chlorogenic acid in primary allergy to castor beans. Int Arch Allergy Appl Immunol 23: 225-238, 1963.

11. Freedman SO, Shulman R, Krupey J and Sehon AH: Antigenic properties of chlorogenic acid. J Allergy 35: 97-107, 1964.

12. Freedman SO: Loss of allergenicity of chlorogenic acid in the gastrointestinal tract. J Allergy 35: 108-116, 1964.

13. Jiang Y, Kusama K, Satoh K, Takayama E, Watanabe S and Sakagami H: Induction of cytotoxicity by chlorogenic acid in human oral tumor cell lines. Phytomedicine 7: 483-491, 2000.

14. Wang L, Cheng L, Yuan Q, Cui X, Shang H, Zhang B and Li Y: Adverse drug reactions of Shuanghuanglian injection: A systematic review of public literatures. J Evid Based Med 3: 18-26, 2010. 
15. Sun SG, Li ZF, Xie YM, Liu J, Lu Y, Song YF, Han YH, Liu LD and Peng TT: Analysis of rational clinical uses of traditional Chinese medicine injections and factors influencing adverse drug reactions. Zhongguo Zhong Yao Za Zhi 38: 2969-2973, 2013 (In Chinese)

16. Wang MX, Liu YY, Hu BH, Wei XH, Chang X, Sun K, Fan JY, Liao FL, Wang CS, Zheng J, et al: Total salvianolic acid improves ischemia-reperfusion-induced microcirculatory disturbance in rat mesentery. World J Gastroenterol 16: 5306-5316, 2010

17. Yuan Y, Guo H, Zhang Y,Zhou D, Gan P, Liang DM and Chen JY: Protective effects of L-carnitine on intestinal ischemia/reperfusion injury in a rat model. J Clin Med Res 3: 78-84, 2011.

18. Wang Y, Jiang YF, Huang QF, Ge GL and Cui W: Neuroprotective effects of salvianolic acid B against oxygen-glucose deprivation/reperfusion damage in primary rat cortical neurons. Chin Med J (Engl) 123: 3612-3619, 2010.

19. Collins-Underwood JR, Zhao W, Sharpe JG and Robbins ME: NADPH oxidase mediates radiation-induced oxidative stres in rat brain microvascular endothelial cells. Free Radic Biol Med 45: 929-938, 2008.

20. Yuan Q, Liu YY, Sun K, Chen CH, Zhou CM, Wang CS, Li A Zhang SW, Ye ZL, Fan JY, et al: Improving effect of pretreatment with yiqifumai on LPS-induced microcirculatory disturbance in rat mesentery. Shock 32: 310-316, 2009.

21. Han JY, Horie Y, Fan JY, Sun K, Guo J, Miura S and Hibi T: Potential of 3,4-dihydroxy-phenyl lactic acid for ameliorating ischemia-reperfusion-induced microvascular disturbance in rat mesentery. Am J Physiol Gastrointest Liver Physiol 296 : G36-G44, 2009 .

22. Han JY, Miura S, Akiba Y, Higuchi H, Kato S, Suzuki H, Yokoyama $\mathrm{H}$ and Ishii $\mathrm{H}$ : Chronic ethanol consumption exacerbates microcirculatory damage in rat mesentery after reperfusion. Am J Physiol Gastrointest Liver Physiol 280: G939-G948, 2001.

23. Zheng LF, Dai F, Zhou B, Yang L and Liu ZL: Prooxidant activity of hydroxycinnamic acids on DNA damage in the presence of $\mathrm{Cu}(\mathrm{II})$ ions: Mechanism and structure-activity relationship. Food Chem Toxicol 46: 149-156, 2008.

24. Crack PJ and Taylor JM: Reactive oxygen species and the modulation of stroke. Free Radic Biol Med 38: 1433-1444, 2005.

25. Dai DZ and Dai Y: Role of endothelin receptor A and NADPH oxidase in vascular abnormalities. Vasc Health Risk Manag 6 : 787-794, 2010
26. Haurani MJ, Cifuentes ME, Shepard AD and Pagano PJ: Nox4 oxidase overexpression specifically decreases endogenous Nox4 mRNA and inhibits angiotensin II-induced adventitial myofibroblast migration. Hypertension 52: 143-149, 2008.

27. Stumpf C, Lehner C, Yilmaz A, Daniel WG and Garlichs CD Decrease of serum levels of the anti-inflammatory cytokine interleukin-10 in patients with advanced chronic heart failure. Clin Sci (Lond) 105: 45-50, 2003.

28. Bolger AP, Sharma R, von Haehling S, Doehner W, Oliver B, Rauchhaus M, Coats AJS, Adcock IM and Anker SD: Effect of interleukin-10 on the production of tumor necrosis factor-alpha by peripheral blood mononuclear cells from patients with chronic heart failure. Am J Cardiol 90: 384-389, 2002.

29. Dokka S, Shi X, Leonard S, Wang L, Castranova V and Rojanasakul Y: Interleukin-10-mediated inhibition of free radical generation in macrophages. Am J Physiol Lung Cell Mol Physiol 280: L1196-L1202, 2001.

30. Schottelius AJ, Mayo MW, Sartor RB and Baldwin AS Jr: Interleukin-10 signaling blocks inhibitor of kappaB kinase activity and nuclear factor kappaB DNA binding. J Biol Chem 274: 31868-31874, 1999.

31. Cook-Mills JM and Deem TL: Active participation of endothelial cells in inflammation. J Leukoc Biol 77: 487-495, 2005.

32. Souza DG, Fagundes CT, Amaral FA, Cisalpino D, Sousa LP, Vieira AT, Pinho V, Nicoli JR, Vieira LQ, Fierro IM, et al: The required role of endogenously produced lipoxin A4 and annexin-1 for the production of IL-10 and inflammatory hyporesponsiveness in mice. J Immunol 179: 8533-8543, 2007.

33. Gunnett CA, Heistad DD, Berg DJ and Faraci FM: IL-10 deficiency increases superoxide and endothelial dysfunction during inflammation. Am J Physiol Heart Circ Physiol 279: H1555-H1562, 2000.

34. Yamaoka M, Yamaguchi S, Okuyama $\mathrm{M}$ and Tomoike $\mathrm{H}$ : Anti-inflammatory cytokine profile in human heart failure: Behavior of interleukin-10 in association with tumor necrosis factor-alpha. Jpn Circ J 63: 951-956, 1999.

This work is licensed under a Creative Commons Attribution-NonCommercial-NoDerivatives 4.0 International (CC BY-NC-ND 4.0) License. 